\title{
The operational issues in the management of drug-resistant TB
}

\author{
Sankalp Yadav ${ }^{1, *}$, Gautam Rawal $^{2}$ \\ ${ }^{1}$ General Duty Medical Officer II, Dept. of Medicine \& TB, Chest Clinic, Moti Nagar, North Delhi Municipal Corporation, New \\ Delhi, ${ }^{2}$ Associate Consultant, Respiratory Intensive Care, Max Super Specialty Hospital, New Delhi, India
}

*Corresponding Author:

Email: drsankalpyadav@gmail.com

The problem of TB is not just confined to the weaker and poorer sections of the society [1]. In fact, no one is spared by this deadly disease that is a now a public health problem [2]. The situation is really grave with an ever-growing number of the drug-resistant TB (DR-TB) cases [3]. As per the WHO, the DR-TB is a manmade problem arising out of an improper administration of DOTS under the RNTCP [4]. The issue is a big problem and could be a serious threat to the national programs aimed at TB elimination by 2025 [5].

Till recently the treatment of DR-TB was being started at the DR-TB centers [6]. Where the patients were admitted for two weeks and the drug regimen was started under the supervision of experts after initial lab workup [6]. However, with recent changes in the Programmatic Management of Drug Resistant TB (PMDT) guideline, the treatment of the same has been diverted to the district TB centers (DTC) [7]. These DTC's have been upgraded to DR-TB centers [7]. This is a novel step towards efforts to eliminate TB [5]. But, the problem with such a move is that the whole process has happened without paying heed to the basic infrastructure of these DTC's. The latest PMDT guidelines clearly mention the need of a pre-treatment evaluation involving a number of lab tests and also opinions from the psychiatrist, ENT specialist and the thoracic surgery/CTVS team [7]. In cases, where a newer drug like Bedaquiline or Delamanid is included in the regimen, then an ophthalmologist's opinion is also mandatory [7].

However, in the current scenario even in the presence of a large number of tertiary government hospitals equipped with lab facilities, it is very difficult for the DR-TB patients to get the relevant lab investigations and opinions from the required departments. The situation is so grave that due to these pending pre-treatment evaluations there could be gaps of around 2-4 weeks to start the DR-TB regimen. This results in an overall impact on the health of the patients, whose health continues to dwindle throughout the whole process [8]. The PMDT guidelines advocate starting the treatment of a TB case without any delays [7]. However, with such delays in starting the DR-TB regimen, the whole process of ramifying the DR-TB treatment from bigger and well equipped DR-TB centers to the DTC looks a near fail attempt.
There are certain efforts to get these pre-treatment evaluations from defined larger (tertiary) centers, where a DR-TB committee is placed who will look after the issues associated with the management of DR-TB cases, yet some of these centers are still missing the departments like thoracic surgery/CTVS where an opinion about lung resection could be given. Also, a number of times the kits for lab tests are not available or the X-ray/ECG machine is not working thus the DRTB patients has to suffer and is required to visit the large centers multiple times. The issue needs attention as these patients are a potential source of infection and thus could create a large number of DR-TB cases in future thereby severely affecting the efforts towards TB-elimination [9]. As these patients are required to get these tests as a routine procedure and are thus made to stand in a queue with the non-TB cases in the large hospitals.

Its noted that in some cases the patients are started on DR-TB regimen with few lab reports out of the all the investigations, but since there are no clear guidelines and no/poor medico-legal backup and with rampant cases of patients taking legal actions against the health facilities, it becomes very difficult to start the DR-TB regimen at the DTC in the absence of complete pre-treatment evaluation [10]. Besides, the pretreatment evaluation is important as it will help in avoiding deadly adverse drug reactions and thus it's totally unethical to start the DR-TB regimen in the absence of the same [11].

Also, these centers where the patients are required to go are far off from their homes and many a time it requires a handsome amount of money to travel to these large hospitals [12]. Thus, having a direct impact on the financial well-being of an already physically and mentally exhausted patient [12]. The patient has to be accompanied with a relative/friend as these patients are very weak thus resulting in loss of wages/time for minimum of two individuals. The issue of stigma associated with TB is also a big contributor to the mental health of the DR-TB case [13].

Besides, there are a number of issues at the health facility (DTC) some of these centers are lacking the basic facilities to manage the life-threatening adverse drug reactions. Some of these DTC's are even lacking a trained chest physician $[8,14]$. The patient transport ambulance is also found missing at some of these centers. 
To sum up there are a number of issues associated with starting a DR-TB regimen at the newly upgraded DTC's. However, in a majority of cases except for the namesake no concrete efforts are made to make the DRTB management patient-friendly. The patients have to travel a lot to get the prerequisite tests done and in most of the cases, the treatment is delayed beyond the permitted PMDT guidelines. The patient in most of the cases becomes so weak that they resort to private practitioners and are thus lost to follow-up. The Government of India should seriously look into this matter and efforts to streamline the whole treatment so as to make it more patient-friendly are imperative. Timely supervision of these new DR-TB centers which were DTC previously is also very important. Overall, the move to diverge a DR-TB control program to the districts is novel one, but currently it has practical problems at the ground level.

Conflicts of interest: None declared Acknowledgements: None

\section{References:}

1. Hargreaves JR, Boccia D, Evans CA, Adato M, Petticrew M, Porter JDH. The social determinants of tuberculosis: from evidence to action. Am J Public Health 2011;101(4):654-62.

2. Yadav S, Rawal G. Active case finding- A new tool in the fight against TB. Ind J Immunol Respir Med 2018;3(1):12.

3. Yadav S, Rawal G. Primary extrapulmonary multidrugresistant tuberculosis in an immunocompetent child presenting with pleural effusion. Transl Pediatr 2017;6(1):72-5.

4. Zumla A, Abubakar I, Raviglione M, Hoelscher M, Ditiu L, Mchugh TD, et al. Drug-resistant tuberculosis- Current dilemmas, unanswered questions, challenges, and priority needs. J Infectious Dis 2012;205:S228-40.

5. Prasad R, Gupta N, Banka A. 2025 too short time to eliminate tuberculosis from India. Lung Ind 2017;34(5):409-10.

6. Akshaya KM, Shewade HD, Aslesh OP, Nagaraja SB, Nirgude AS, Singarajipura A, Jacob AG. "Who has to do it at the end of the day? Programme officials or hospital authorities?" Airborne infection control at drug resistant tuberculosis (DR-TB) centres of Karnataka, India: a mixed-methods study. Antimicrob Resist Infect Control 2017;6:111.

7. Programmatic Management of Drug Resistant TB (PMDT). Available from URL: -https://tbcindIa. gov.in/showfile.php?lid=3155. Accessed 2018 on September 6.

8. Adenager GS, Alemseged F, Asefa H, Gebremedhin AT. Factors Associated with Treatment Delay among Pulmonary Tuberculosis Patients in Public and Private Health Facilities in Addis Ababa, Ethiopia. Tuberc Res Treat 2017;2017:5120841.

9. Bantubani N, Kabera G, Connolly C, Rustomjee R, Reddy T, Cohen T, et al. High Rates of Potentially Infectious Tuberculosis and Multidrug-Resistant Tuberculosis (MDR-TB) among Hospital Inpatients in KwaZulu Natal, South Africa Indicate Risk of Nosocomial Transmission. PLoS One 2014;9(3):e90868.
10. Raveesh BN, Nayak RB, Kumbar SF. Preventing medicolegal issues in clinical practice. Ann Ind Acad Neurol 2016;19(Suppl 1):S15-S20.

11. Gholami K, Kamali E, Hajiabdolbaghi M, Shalviri G. Evaluation of anti-tuberculosis induced adverse reactions in hospitalized patients. Pharm Pract (Granada). 2006;4(3):134-38.

12. Cai J, Wang X, Ma A, Wang Q, Han X, Li Y. Factors associated with patient and provider delays for tuberculosis diagnosis and treatment in Asia: A systematic review and meta-analysis. PLoS One 2015;10(3):e0120088.

13. Pungrassami P, Kipp AM, Stewart PW, Chongsuvivatwong V, Strauss RP, Van Rie A. Tuberculosis and AIDS stigma among patients who delay seeking care for TB symptoms. Int J Tuberc Lung Dis 2010;14(2):181-87.

14. Bogale S, Diro E, Shiferaw AM, Yenit MK. Factors associated with the length of delay with tuberculosis diagnosis and treatment among adult tuberculosis patients attending at public health facilities in Gondar town, Northwest, Ethiopia. BMC Infect Dis 2017;17:145.

How to cite this article: Yadav S., Rawal G. The operational issues in the management of drugresistant TB. IP Indian J Immunol Respiratory Med 2018;3(3):156-157. 